\title{
Research on the Cost of the Whole Life Cycle of the Transformer
}

\author{
Yong Yang ${ }^{a}$, Jing-jing Zheng ${ }^{b}$, Pei-dong $\mathrm{Du}^{\mathrm{c}}{ }^{\text {, Jing Peng }}{ }^{\mathrm{d}}$ \\ Gansu Electric Power Research Institute, Guangzhou 510000, China; \\ ayy8801@126.com, jingjing110@163.com, ${ }^{\mathrm{c}}$ dpdong@126.com, ${ }^{\mathrm{d}}$ pengjing19871028@163.com
}

Keywords: Full life cycle; case; modeling; analysis.

\begin{abstract}
To solve the current energy supply and demand tension grid must intelligent control to the operation of the equipment, at the same time, to look for a new management model, to maximize energy efficiency, to achieve energy-saving power grid. Transformer is the most important power equipment, domestic study on transformer life currently mainly concentrated in the transformer life cycle cost, type selection of transformer and the transformer economic operation. In this paper, we consider transformer in the demonstration, construction, operation, maintenance, fault, and maintenance until his retirement in the whole life process, the modeling, through an example analysis to estimate the life cycle energy consumption.
\end{abstract}

\section{Introduction}

In recent years, China's economy maintained rapid growth, energy demand has increased rapidly, electric power industry is facing increasingly serious resource shortage problem. At the same time, the world has begun exploring study of energy-efficient power grid. In order to adapt to the needs of the times, to solve the current situation of energy supply and demand, the power grid must be intelligent control of running equipment, while looking for new management mode, to maximize the energy efficiency, to achieve power grid ${ }^{[1]}$. According to the statistics of the equipment in recent years, the average operating life of the transformer is 18.1 years.

With the accelerated development of power grid assets, operation, maintenance, update, transformation tasks become more and more heavy, the traditional management mode has been unable to adapt to the new situation of development, strengthen asset management has become a priority among priorities of power grid enterprise management. The main equipment of the initial investment, operation manual and maintenance costs are high, service the characteristics of a long time, which has broad application prospects of life cycle cost management ${ }^{[2]}$. The cost management of the whole life cycle from the perspective of power grid enterprises, helps power enterprises to get rid of the traditional cost management concept, in order to build a new cost management system, to ensure the safety of power grid and improve power grid the use of assets efficiency and energy efficiency, reduce the life cycle energy consumption, realize the power grid equipment lean, the whole process of comprehensive management ${ }^{[3]}$.

\section{The concept of life cycle cost}

The whole Life Cycle cost (Life Cycle Costs, LCC) considering the assets from the purchase, operations, maintenance, and retired the total cost of each process. Therefore, through the establishment of total assets Life Cycle Management based on LCC (Life Cycle Asset Management, LCAM) evaluation model to support enterprise decision-making, will be conducive to achieve the Management of the enterprise benefit maximization.

Full life cycle theory considers the equipment (assets) from the production, installation, commissioning, operation, maintenance, fault, each link of life cycle, such as is a comprehensive and systematic analysis method.

Full life cycle theory in the field of asset management has great significance for the purposes of this research project. The state grid corporation is given total Assets Life Cycle Management (Life Cycle Assets Management, LCM) refers to the "starting from the long-term economic benefits of enterprises, through a series of technical measures of economic organization of equipment planning, design, 
manufacture, purchase, installation, commissioning, operation, maintenance, modification, update until the whole process of scrap for comprehensive Management, at the same time, the power grid security in the efficiency of the whole process of cost control, make the minimum Life Cycle cost of the Management concept. The core content of LCM is within the scope of the equipment Life Cycle how to develop and implement coordinated the most valuable enterprise asset usage and maintenance decisions.

In the power industry of the whole Life Cycle management of assets, we consider the whole Life Cycle Cost of the asset (Life Cycle Cost, LCC). LCC can be expressed as

$$
\mathrm{LCC}=\mathrm{CI}+\mathrm{CO}+\mathrm{CM}+\mathrm{CF}+\mathrm{CD}
$$

Among them, the CI for Investment costs (the Cost of Investment), CO for running costs (Cost of Operation), the CM for overhaul Maintenance costs (the Cost of Maintenance), CF for Failure costs (the Cost of Failure), CD for decommissioning disposal costs (the Cost of the Discard). The above each cost can also be more detailed decomposition according to different types of devices ${ }^{[4]}$.

The main points of the LCC theory is: through unified management of technology and economy, to quantify the data to make decisions, achieve a comprehensive planning, rational allocation, preferential purchase, use the correct, careful maintenance, scientific maintenance, timely renewal, so that equipment in good condition, from input and output to ensure minimum of LCC.

At present, in the field of energy-saving emission reduction, a full life cycle analysis more for calculation and analysis of energy consumption and carbon emissions. In the whole life cycle of the power industry analysis of most of the achievements from abroad, domestic for the full life cycle energy consumption and carbon emission analysis is currently limited in two aspects: one is the energy structure analysis for comparison of electric energy in the terminal energy consumption advantages; the second is the new energy vehicles and traditional automobile energy efficiency and carbon emissions characteristics of contrast.

According to the whole life cycle of the classical analysis method, the equipment of the whole life cycle energy consumption can be decomposed into

$$
\mathrm{LCEC}=\mathrm{ECI}+\mathrm{ECO}+\mathrm{ECM}+\mathrm{ECF}+\mathrm{ECD}
$$

Type of LCEC Energy consumption for the whole Life Cycle (Life Cycle Energy Cost), ECI for Investment in Energy consumption, Energy Cost of Investment), ECO for running Energy consumption (Energy Cost of Operation), the ECM for Maintenance Energy (Energy Cost of Maintenance), ECF for fault Energy (Energy Cost of Failure), ECD for retired Energy (Energy Cost of the Discard). The ECI, ECO, ECM, ECF and ECD can be further subdivided according to actual situation.

When conventional energy load capacity can't meet the new energy development in hexi area, can take advantage of the high load can load to calm wind power fluctuations, the large-scale new energy power generation can be given on the spot, which have the effect of peak peel. However, different ways of high load can load connected to the electricity grid, will have different influence on the grid, and balances of supply and demand of the electric power and power grid have great influence of network loss ${ }^{[5]}$.

\section{Modeling of full life cycle of transformer}

Comprehensive consideration of the transformer in the demonstration, construction, operation, maintenance, fault, maintenance until his retirement in the whole life process, overall consideration in every process impact sensitivity indices of energy consumption factors, combined with the characteristics of the operation of transformer, the transformer life cycle energy consumption decomposition into several stages and the modeling ${ }^{[6]}$.

\section{Application example of full life cycle of power network equipment}

This study combined with the current operating situation of Gansu multiple counties $110 \mathrm{kV}$ distribution network transformer, through the collection of the basic technical parameters of $110 \mathrm{kV}$ 
transformer in the operation process of the number of failures such as parameters, cost quantitative estimates to set up the $110 \mathrm{kV}$ model of life cycle cost, carry out the whole life management of $110 \mathrm{kV}$ transformer equipment. Estimating model of energy consumption in LCEC in the present situation, the design life of a comprehensive analysis of different equipment manufacturers of $110 \mathrm{kV}$ transformer and the average service life, access to relevant literature, assuming the $110 \mathrm{kV}$ divider design life of 30 years, the electric power market average price level of 0.50 yuan $/ \mathrm{kWh}$. in Gansu province a distribution station in $110 \mathrm{kV}$ three-phase transformer selection as an example, scheme A, $\mathrm{B}$, basic technical parameters of transformer $\mathrm{C}$ scheme are shown in Table 1.

Table 1 Basic parameters of $110 \mathrm{kv}$ three-phase transformer

\begin{tabular}{|c|c|c|c|}
\hline transformer & Plan A & PlanB & Plan C \\
\hline Voltage level (kV) & 110 & 110 & three-phase \\
\hline Equipment Phase & three-phase & three-phase & SSZ10-63000/110 \\
\hline Model name & SFPSZ10-63000/110 & SFSZ9-63000/110 & joint venture \\
\hline Manufacturer types & joint venture & joint venture & 0.91 \\
\hline No-load current (\%) & 0.84 & 0.84 & 65 \\
\hline No-load loss (kW) & 58 & 60 & 63 \\
\hline High capacity (MVA) & 63 & 63 & 63 \\
\hline Medium voltage capacity (MVA) & 63 & 63 & Oil-immersed self-cooled \\
\hline Low voltage capacity (MVA) & 63 & 63 & 11 \\
\hline Cooling way & Air-cooled natural circulation & Air-cooled natural circulation & 271 \\
\hline Connection group & 11 & 11 & 63 \\
\hline Short circuit loss (kW) & 270 & 255 & On-load voltage regulating \\
\hline Main transformer capacity (MVA) & 63 & 63 & On-load voltage regulating \\
\hline Regulating way & On-load voltage regulating & & 53 \\
\hline
\end{tabular}

\subsection{Comparison of energy consumption of transformer initial investment.}

On the basis of the project to build the investment consumption model, the basic parameters to provide a power supply company in Gansu Province, $110 \mathrm{kV}$ distribution transformer, the original value of the assets, capacity, operation time, manufacturing units, no-load current and no-load loss, short circuit loss each variable data. Data provide unit requirements, writing a paper lists only part of the data, as shown in Table 2.

Table 2 Part of the $110 \mathrm{kv}$ transformer basic technical parameters

\begin{tabular}{|c|c|c|c|c|c|c|}
\hline $\begin{array}{c}\text { Capacity } \\
\text { (MV) }\end{array}$ & $\begin{array}{c}\text { The elapsed time } \\
\text { (years) }\end{array}$ & $\begin{array}{c}\text { Manufacturing } \\
\text { unit }\end{array}$ & $\begin{array}{c}\text { The original value of the } \\
\text { asset }\end{array}$ & $\begin{array}{c}\text { No-load } \\
\text { current }\end{array}$ & $\begin{array}{c}\text { No-load loss } \\
\text { Short circuit } \\
\text { loss }\end{array}$ \\
\hline 63 & 3 & 3 & 1778 & 0.84 & 58.88 & 270 \\
\hline 63 & 3 & 3 & 1713 & 0.5 & 61.6 & 270 \\
\hline 63 & 12 & 1 & 725 & 0.63 & 56.8 & 234 \\
\hline 63 & 3 & 2 & 1337 & 0.4 & 52 & 234 \\
\hline 63 & 1 & 1 & 1240 & 0.5 & 56.8 & 222.3 \\
\hline 63 & 3 & 2 & 1093 & 0.91 & 41.48 & 189 \\
\hline 40 & 4 & 3 & 1002 & $\cdots$ & $\ldots$ & $\cdots$ \\
\hline$\cdots$ & $\cdots$ & $\cdots$ & 1043 & 0.55 & 43.6 & 189 \\
\hline 40 & 12 & 1 & 1778 & 0.7 & 40.4 & 156.6 \\
\hline 40 & 4 & 2 & 1240 & 0.09 & 36.8 & 156.6 \\
\hline 40 & 1 & 1 & 762 & 0.5 & 40.4 & 149 \\
\hline 40 & 12 & 1 & 265 & 0.55 & 36.8 & 149 \\
\hline 40 & 5 & 1 & $\ldots$ & & & \\
\hline
\end{tabular}

Used statistical analysis software SPSS stepwise regression, the significant levels of alpha $=0.05$, the total number of sample data set and the number of variables can be elected to the critical value $\mathrm{F}=$ 4.45, excluding the critical value $\mathrm{F}=4.41$. Variable $\mathrm{x} 1$ and $\mathrm{x} 5$, $\mathrm{x} 6$, namely, the capacity of transformer, no-load loss and short circuit losses have relevance to its initial investment in energy consumption, 
thus establishing $\mathrm{y}$ (the original value of the asset) and how far between $\mathrm{x} 1$ and $\mathrm{x} 5$, $\mathrm{x} 6$ regression equation, the equation is as follows:

$$
\mathrm{Y}=-24.915 \mathrm{X}_{1}+14.314 \mathrm{X}_{2}+8.24 \mathrm{X}_{3}+81
$$

Based on the initial investment model and the $110 \mathrm{kV}$ transformer basic technical parameters, the operation status of the $110 \mathrm{kV}$ transformer is analyzed, and the initial investment energy consumption of the three schemes is estimated as shown in Table 3.

Table 3 three schemes of the initial investment in energy consumption analysis table

\begin{tabular}{|c|c|c|c|}
\hline transformer & Plan A & Plan B & Plan C \\
\hline High capacity(MVA) & 63 & 63 & 63 \\
\hline No-load loss (kW) & 58 & 60 & 55 \\
\hline Short circuit loss (kW) & 270 & 255 & 271 \\
\hline Energy consumption of the initial investment (ten thousand yuan) & 1568 & 1473 & 1533 \\
\hline To compare & \multicolumn{3}{|c|}{ A > C > B } \\
\hline
\end{tabular}

\subsection{Comparison of energy consumption of transformer operation.}

Current transformers are commonly exist two kind of way of overhauling. Grey relational analysis theory on the basis of the mentioned, respectively of $110 \mathrm{kV}$ transformer condition based maintenance and periodic overhaul two maintenance and operation cost model were based on Grey Relational Analysis and modeling ${ }^{[7]}$.

Combined with the actual substation main transformer research results, considering the operation status of the transformer, the estimated results of the three programs in the operation process of the transformer are shown in Table 4.

Table 4 transformer operation energy consumption comparison results

\begin{tabular}{|c|c|c|c|}
\hline transformer & Plan A & Plan B & Plan C \\
\hline Energy (ten thousand yuan) & 746.82 & 921.5 & 840.6 \\
\hline To compare & \multicolumn{3}{|c|}{ B > C > A } \\
\hline
\end{tabular}

\subsection{Comparison of energy consumption of transformer fault.}

According to the established fault model of energy consumption, the introduction of grey system theory prediction for transformer, the average failure number. Table 8 statistics for a transformer in 2012 and put into operation since the average annual number of failures, combined with grey system theory to predict the scheme of a transformer in the total number of failures in life cycle in the past 30 years.

Table 5 schemes in a transformer fault data statistics results

\begin{tabular}{|c|c|}
\hline Operating life & The annual average failure number \\
\hline 1 & 0.015 \\
\hline 2 & 0.0137 \\
\hline 3 & 0.01294 \\
\hline 4 & 0.011865 \\
\hline 5 & 0.011 \\
\hline 6 & 0.016589 \\
\hline 7 & 0.0186 \\
\hline 8 & 0.019231 \\
\hline 9 & 0.02963 \\
\hline
\end{tabular}

\subsection{Comparison of energy consumption of transformer in power transformer.}

According to the establishment of the transformer model of power consumption, the estimated results of the three types of transformer scrap costs as shown in Table 7. 
Table 7 three-phase transformer scrap cost estimate table

\begin{tabular}{|c|c|c|c|}
\hline transformer & Plan A & Plan B & Plan C \\
\hline Cost factor & 0.15 & 0.15 & 0.15 \\
\hline Energy consumption of the initial investment & 1568.456 & 1473.368 & 1533.762 \\
\hline Design life & 30 & 30 & 30 \\
\hline Retired energy consumption (ten thousand yuan) & -235.268 & -221.005 & -230.064 \\
\hline To compare & & B $>\mathrm{C}>\mathrm{A}$ \\
\hline
\end{tabular}

\subsection{Comparison of energy consumption of transformer LCEC}

According to the estimated results of the cost of each stage, the results of the three kinds of the whole life cycle cost estimation of the transformer are obtained as shown in Table 8.

Table 8 transformer LCEC estimate table

\begin{tabular}{|c|c|c|c|}
\hline transformer & Plan A & Plan B & Plan C \\
\hline Energy consumption of the initial investment & 1568.456 & 1473.368 & 1533.762 \\
\hline Energy consumption & 746.82 & 921.5 & 840.6 \\
\hline Energy consumption of the fault & 84.99 & 84 & 78.2 \\
\hline Retired energy consumption & -235.268 & -221.005 & -230.064 \\
\hline LCEC & 2164.998 & 2257.863 & 2222.498 \\
\hline To compare & \multicolumn{3}{|c|}{ B > C > A } \\
\hline
\end{tabular}

Three-phase transformer selection and comparison, the scheme of a transformer of full life cycle energy consumption estimates for 2164.998 million yuan, than the plan B type transformer cost savings 92.865 million yuan, than the $C$ type transformer cost saving 57.5 million yuan, visible from the point of view of economy, the choice of transformer, a plan should be preferred. Combined with the actual transformer operation condition, consistent with the selection result and the project practice. Therefore, the feasibility of the model is higher.

\section{Conclusion}

Life cycle asset management as a new management mode is an emphasis on asset management of the life cycle of the overall management and its departure from the long-term benefits, assets in the whole life cycle benefit / cost optimal. Undertaking the life cycle management of power grid assets will in ensuring the rational planning, engineering quality, network security, reliable equipment at the same time, extend asset life, reduce the whole life cycle cost investment, realize the comprehensive optimization of the reliability and economy of power assets, avoid one-sided pursuit of reliability or economy.

\section{References}

[1]. Winter. All under the perspective of life cycle cost of power grid enterprise cost management research: [D]. Shandong, Shandong University, 2006.( in Chinese)

[2]. The king publication, shu qin. Use the homework cost method for supplier selection and evaluation [J]. J - CIMS computer integrated manufacturing system, 2001, (7) : 53-57. ( in Chinese)

[3]. Yi-min jiang jun ma. Transformer of whole life cycle cost analysis [J]. Journal of transformer, lancet, 2006 (12): 30-35. ( in Chinese)

[4]. Jiang Wenjin hai-hua Chen, ShiGuangYu. Based on the total life cycle cost of the main transformer substation selection [J]. Journal of fujian electric power with the electrician, 2009, 1:21-23. ( in Chinese) 
[5]. Cai Bo. With the whole life cycle cost method to choose the subway transformer Yin. Electrified railway, 2005, 5:35-40. ( in Chinese)

[6]. Ma, tian-xiang han, yao, etc., and LCC substation 220 kvgis equipment reconstruction after assessment study [J]. Journal of east China electric power, 2005 (12): 15 to 19. (in Chinese)

[7]. Zhao Hong Lu Yongping, Ma Weiqing, etc. Based on the circuit breaker reliability of LCC analysis [J]. Journal of modern electric power, 2009, 5:89-92. ( in Chinese)

[8]. Yong-ping du, hong-ze li, Zhao Hong, etc. High voltage circuit breaker overhaul and technical transformation project of optimization [J]. Journal of Anhui technical college of electrical engineering, 2010, 15 (1): 1-7. ( in Chinese) 